\title{
Ulcerative Colitis and Acute Thrombocytopenia in a Pediatric Patient: A Case Report and Review of the Literature
}

\author{
Bronislava Papadatou ${ }^{*}$, Fiammetta Bracci1 ${ }^{1}$, Daniela Knafelz1, Antonella Diamanti', \\ Maria Sole Basso', Fabio Panetta1, Filippo Torroni' ${ }^{2}$, Valerio Nobili3 ${ }^{3}$, Giuliano Torre ${ }^{1}$ \\ ${ }^{1}$ Gastroenterology, Hepathology and Nutrition Unit, "Bambino Gesù" Children's Hospital, Rome, Italy \\ ${ }^{2}$ Gastroenterology, Digestive Surgery and Endoscopy Unit, "Bambino Gesù" Children's Hospital, Rome, Italy \\ ${ }^{3}$ Gastroenterology, Hepato-metabolic Diseases Unit, "Bambino Gesù" Children's Hospital, Rome, Italy \\ Email: ${ }^{*}$ antonella.diamanti@opbg.net
}

Received 16 April 2014; revised 30 May 2014; accepted 16 June 2014

Copyright (C) 2014 by authors and Scientific Research Publishing Inc.

This work is licensed under the Creative Commons Attribution International License (CC BY). http://creativecommons.org/licenses/by/4.0/

(c) (i) Open Access

\begin{abstract}
We report the case of a 14-year-old boy affected by ulcerative colitis (UC) and acute thrombocytopenic purpura (ITP) with simultaneous onset. UC diagnosis was based on symptoms, endoscopy and histology findings. ITP diagnosis was based on the normal bone marrow megakaryocyte count, the presence of platelet associated IgG and the absence of splenomegaly. Medical treatments including high doses of steroids, intravenous immunoglobulins were ineffective on ITP course, while UC course was mild for several months after the onset. When colonic inflammation became untractable not responsive at steroids and immunosuppressive agents, colectomy resolved both pathologies.
\end{abstract}

Keywords

Ulcerative Colitis, Thrombocytopenia, Children

\section{Introduction}

Ulcerative colitis (UC) is a chronic inflammatory bowel disease (IBD) frequently associated with extra-intestinal manifestations and various autoimmune disorders [1] [2]. Autoimmune antibody-mediated hematologic diseases such as autoimmune hemolytic anemia have been reported in patients with IBD, both in UC and in Crohn's disease (CD) [3]-[6]. Immune thrombocytopenic purpura (ITP), defined as low platelet count in the absence of

*Corresponding author.

How to cite this paper: Papadatou, B., Bracci, F., Knafelz, D., Diamanti, A., Basso, M.S., Panetta, F., Torroni, F., Nobili, V. and Torre, G. (2014) Ulcerative Colitis and Acute Thrombocytopenia in a Pediatric Patient: A Case Report and Review of the Literature. Health, 6, 1497-1502. http://dx.doi.org/10.4236/health.2014.612184 
other clinically apparent causes of thrombocytopenia and caused by antibody-mediated platelet destruction, has been sporadically reported in adult patients affected by IBD [7]. Association between ITP and IBD in children is rarely described.

Onset clinic manifestation of both diseases could be presented by gastrointestinal bleeding.

UC treatment with steroids and immunosuppressive drugs is usually effective to treat ITP. Medical therapy of ITP includes besides corticosteroids and immunosuppressive agents such as cyclosporine and azathioprine, intravenous immunoglobulins. Recently infliximab has also been reported as a successful treatment for immune mediated extraintestinal manifestations of UC refractory to other interventions [8] [9].

We report the case of a boy with UC and refractory ITP, in whom colectomy resolved both diseases.

\section{Case Report}

A 14-year-old boy, without evidence of problems in the past medical history, was admitted to "Bambino Gesù" Children Hospital of Rome with a 15 days history of bloody diarrhea and abdominal pain. No bleeding from other organs was present. There was no evidence of purpura and mucosal petechiae. Family history was unremarkable.

Initial laboratory evaluation showed: hemoglobin $12 \mathrm{~g} / \mathrm{dl}$ (normal values $13-16 \mathrm{~g} / \mathrm{dl}$ ), hematocrit 33.6\% (36\% - 49\%), white blood cell count 4350/ml (4000 - 13,500/ml), platelet count $38 \times 10^{3} / \mathrm{mm}^{3}\left(150-450 \times 10^{3} / \mathrm{mm}^{3}\right)$, moderate elevation of CRP and ESR levels. The assessment of the coagulation resulted into the normal ranges. ASCA-IgA and IgG, ANCA, antinuclear and anti-dsDNA antibodies resulted absent. Platelet-associated antibodies were present (antibodies anti GPIIb/IIIa, antibodies anti GPIa/IIa and antibodies anti GPIb/IX). Heterozygosis of MTHFR (C677T) was present. Stool evaluation was negative for infectious pathogens, virus, Clostridium Difficile and its toxin. Fecal calprotectin levels raised up to 3550 microg/gr (NV < 250 microg/gr).

Bone marrow biopsy revealed a normocellular marrow with a normal number of megakaryocytes. Hepatotropic viruses (B and C hepatitis) and cytomegalovirus, Ebstein-Barr virus, HHV-6 and parvovirus infections in blood and bone marrow were ruled out. No splenomegaly was found on abdominal ultrasonography. Upper endoscopy showed hemorrhagic gastritis and absence of Helicobacter Pylori. Colonoscopy showed macroscopic inflammation extending from cecum to rectum (pancolitis). Terminal ileum mucosa resulted normal. Histopathology confirmed the diagnosis of UC (see Figure 1). Treatment with 5-aminosalicylic acid and intravenous prednisolone at the dose of $1.5 \mathrm{mg} / \mathrm{Kg} /$ day was begun. There was a rapid improvement of gastrointestinal symptoms and an increase in platelet count, up to $63 \times 10^{3} / \mathrm{mm}^{3}$.

During the follow-up the platelet count remained stable around $40 \times 10^{3} / \mathrm{mm}^{3}$, but decreased to $20 \times 10^{3} / \mathrm{mm}$ when reduction of steroids was attempted. No resolution of his thrombocytopenia was obtained with a course of intravenous immunoglobulins and steroid treatment was continued at the dose of $1 \mathrm{mg} / \mathrm{Kg} / \mathrm{day}$.

This resulted in a good control of the child's UC with a stable Pediatric Ulcerative Colitis Activity Index (PUCAI) below 10 [10]. Endoscopy performed three months after the diagnosis showed a normal mucosa, and histopathology confirmed the remission of the inflammatory process.

Eight months later during a further attempt to reduce steroids the patient presented bloody diarrhea with more than 15 bowel movements/day and severe abdominal pain. Colonoscopy showed severe relapse of the UC.

Total parenteral nutrition, antibiotics and intravenous cyclosporine as a rescue therapy was began. Symptoms persisted, the patient needed blood transfusion, and the PUCAI score after 5 days of therapy was 80, platelets count was $29 \times 10^{3} / \mathrm{mm}^{3}$ Surgical treatment was considered necessary as the disease was life-threatening and total colectomy was performed. Histology of the resected colon was in keeping with a diagnosis of severe, acute UC (see Figure 2 and Figure 3).

Steroids were tapered in few days and patient was discharged. Two months after colectomy, platelet count improved and reached $85 \times 10^{3} / \mathrm{mm}^{3}$. Six months afterwards was $150 \times 10^{3} / \mathrm{mm}^{3}$ and at 10 months platelet count was normal $\left(240 \times 10^{3} / \mathrm{mm}^{3}\right)$.

The informed consent was obtained from the patient and his family to report this case

\section{Discussion}

The association of IBD with ITP is rare and it has been recently recognized and described. Since the first description by Edwards and Truelove in 3 adult patients among 624 adults affected by UC, few occasional cases have been published [8] [9] [11]-[24]. Only 8 papers report of pediatric patients [12] [14] [22] [23]. We de- 


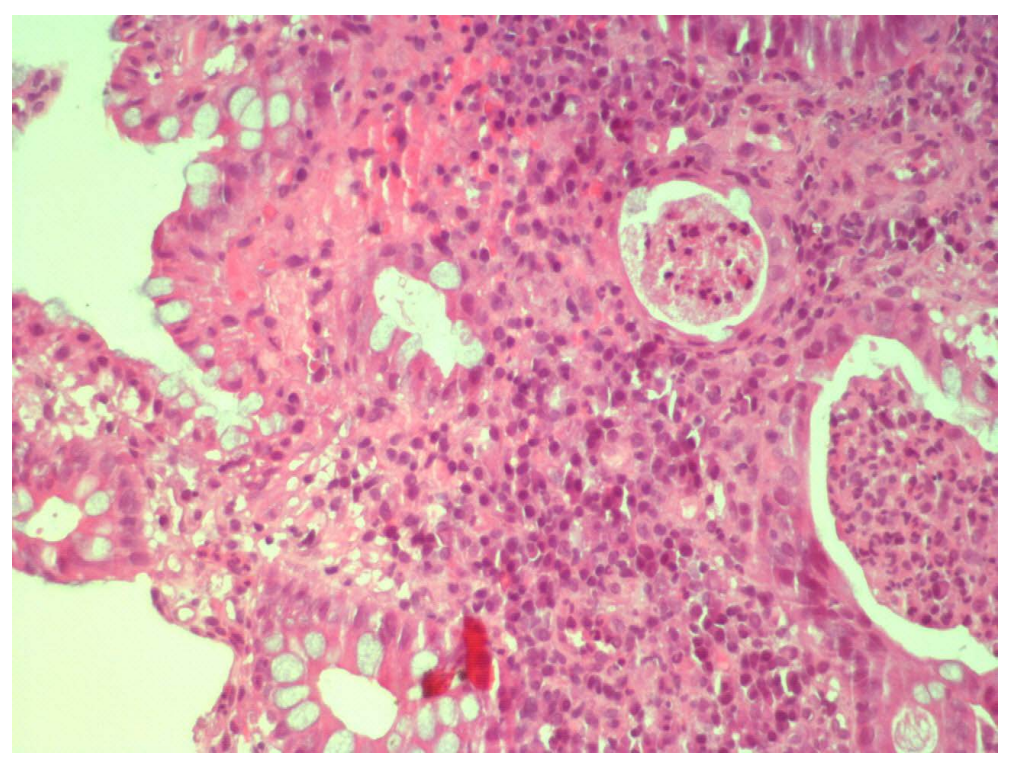

Figure 1. Histopathological features of active ulcerative colitis from endoscopic biopsy specimens.

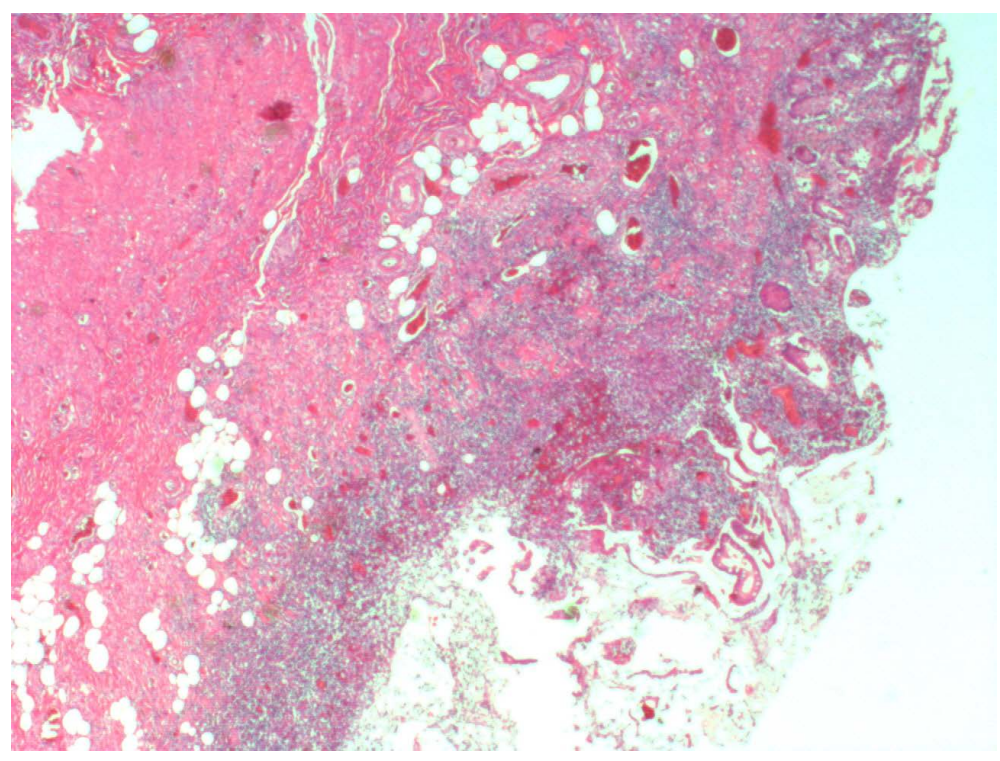

Figure 2. Histopathological features of active ulcerative colitis from colectomy specimens.

scribed one more pediatric patient in whom UC and ITP had a simultaneous onset. The diagnosis of UC in our patient was based on symptoms, endoscopy and histology findings. The diagnosis of ITP was based on bone marrow examination that revealed a normal megakaryocyte number, the presence of platelet-associated IgG, and absence of splenomegaly. There was no evidence of any hematological disease, infection or immune deficiency. Disseminated intravascular coagulation (DIC) was ruled out by the presence of normal prothrombin time and normal levels of fibrinogen and fibrin degeneration products.

ITP in our patient had a partial response to high doses of steroids, with platelets number rising up to $60 \times$ $10^{3} / \mathrm{mm}^{3}$ during full steroid treatment, while every attempt to reduce the dose was followed by a fall in the platelet count. It has been postulated that thrombocytopenia with platelet associated antibodies occurs during a severe relapse of UC. On the other hand increased colonic permeability to luminal antigens may produce antibodies which may result in cross-reactivity with platelet antigens, resulting in platelet destruction. This would be 


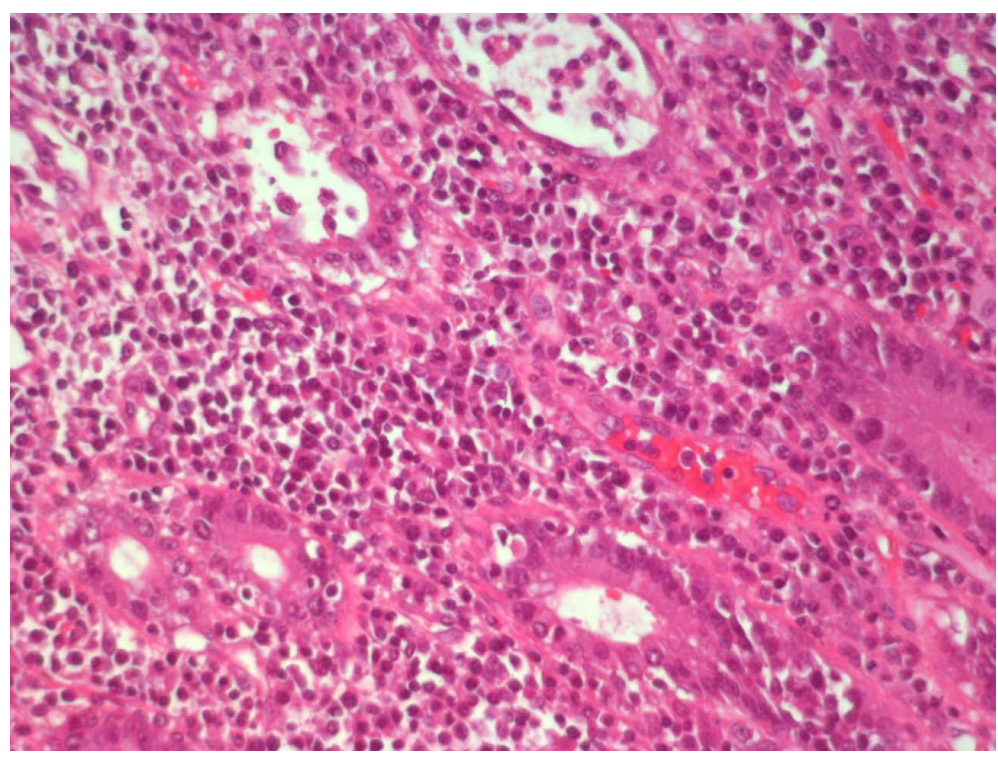

Figure 3. Findings of acute ulcerative colitis from specimens taken during the surgery.

true during an acute exacerbation because of enhanced exposure to luminal antigens and that is what happens in the majority of cases of ITP associated with IBD [12]. On the contrary of what is reported in the literature, in our case low number of platelets were not associated, at least during the first months of the disease, with exacerbation of gastrointestinal symptoms and colonoscopy performed during his minimal platelet count $\left(20 \times 10^{3} / \mathrm{mm}^{3}\right)$ showed an improvement of mucosal injury. It is any way possible that, once activated the autoimmune mechanism, a subclinical injury of the mucosa may perpetuate the ITP.

Several treatments have been used in the management of both diseases. Courses with steroids in association with mesalazine have been frequently able to induce remission of both diseases. Sometimes high doses of steroids, immunosuppressive agents and intravenous immunoglobulin or splenectomy have been required to control ITP [12] [13] [25]-[28].

For at least eight months our patient obtained a good control of his colitis with mesalazine and steroids while ITP was partially controlled even during clinical and histological remission of colitis. The relapse of his colitis was severe and a rescue medical therapy became necessary. Intravenous Cyclosporine A (CyA) was started at the dose of $3 \mathrm{mg} / \mathrm{kg} / \mathrm{day}$. CyA has been effectively used for the treatment of severe steroid-refractory UC [10] [29] [30] and it has also been reported to be useful in patients with corticosteroid and splenectomy-refractory ITP [26]. In our patient rescue therapy with IV CyA was unsuccessful and surgery was unavoidable. Colectomy was resolutive for both pathologies. Platelets number gradually rose after surgery — when all medical therapies were stopped-and reached sub-optimal levels within 6 months after colectomy. The platelet count was completely normalized 10 months after colectomy and continued to be normal during the follow up of almost 18 months. In the past six adult patients affected by ITP and UC have been described to undergo colectomy, in five of them the surgical intervention was resolutive for both ITP and UC [15]-[18] [21]. Higoushi et al. reported four pediatric cases of UC and ITP one of which underwent colectectomy because of fulminant colitis unresponsive to medical treatment. Medical therapy was stopped after surgery but she continued to have episodes of thrombocytopenia treated with IV Ig and steroid [12]. In another pediatric patient ITP developed after colectomy [20]. Hisada et al reported a case of acute ITP associated with preexisting ulcerative colitis in a 36-year-old man in whom colectomy was performed at the patient's request because of life-threating colonic hemorrhage without attempt a rescue therapy with intravenous cyclosporine or infliximab and resulted in cure of both diseases [19].

A recent Italian survey described the phenotype and disease course of pediatric onset UC diagnosed at a tertiary referral Center for Pediatric Gastroenterology. In this retrospective evaluation, 14\% out of the 110 involved underwent. The presence of extensive disease, severe colitis and need of corticosteroids at the diagnosis were associated in this study with an increased risk of colectomy [31]. Our patient had all the risk factors that can lead to approach the surgical option. 


\section{Conclusion}

In conclusion we have reported for the first time the case of a pediatric patient with UC and thrombocytopenia who did not respond to the medical treatment in which colectomy has been resolutive for both diseases. We therefore consider that colectomy must be considered in children when both diseases are resistant to intensive medical management.

\section{References}

[1] Hyams, J. (1994) Extraintestinal Manifestations of Inflammatory Bowel Disease in Children. Journal of Pediatric Gastroenterology and Nutrition, 19, 7-12. http://dx.doi.org/10.1097/00005176-199407000-00003

[2] Levine, J. and Lukawski-Trubish, D. (1995) Extraintestinal Considerations in Inflammatory Bowel Disease. Gastroenterology Clinics of North America, 24, 633-645.

[3] Gumaste, V., Greenstein, A.J., Meyers, R., et al. (1989) Coombs-Positive Autoimmune Hemolytic Anemia in Ulcerative Colitis. Digestive Diseases and Sciences, 34, 1457-1461. http://dx.doi.org/10.1007/BF01538085

[4] Snook, J.A., de Silva, H.J. and Jrwell, D.P. (1989) The Association of Autoimmune Disorders with Inflammatory Bowel Disease. Quarterly Journal of Medicine, 72, 835-840.

[5] Yu, L.Z., Qian, S., Hong, M., Liu, P. and Li, J. (2010) A Case of Ulcerative Colitis Associated with Autoimmune Hemolytic Anemia Successfully Treated by Autologous Hematopoietic Stem Cell Transplantation. The American Journal of Gastroenterology, 105, 2302-2304. http://dx.doi.org/10.1038/ajg.2010.221

[6] Molnár, T., Farkas, K., Szepes, Z., Nagy, F. and Wittmann, T. (2010) Autoimmune Hemolytic Anemia Associated with Ulcerative Colitis: The Most Important Step Is to Induce Complete Remission. The American Journal of Gastroenterology, 105, 1203-1204. http://dx.doi.org/10.1038/ajg.2009.751

[7] Stasi, R., Evangelista, M.L., Stipa, E., Buccisano, F., Venditti, A. and Amadori, S. (2008) Idiopathic Trombocytopenic Purpura: Current Concepts in Pathophysiology and Management. Thrombosis and Haemostasis, 99, 4-13.

[8] Edwards, F.C. and Truelove, S.C. (1964) The Course and Prognosis of Ulcerative Colitis: Part III Complications. Gut, 5, 1-15.

[9] Zlatanic, J., Korelitz, B.I., Wisch, N., Kim, P., Ammirati, M., Schwarz, S., Gruenstein, S. and Lipsey, L. (1997) Inflammatory Bowel Disease and Immunune Thrombocytopenic Purpura: Is There a Correlation? The American Journal of Gastroenterology, 92, 2285-2288.

[10] Turner, D., Travis, S., Griffiths, A., Ruemmele, F., Levine, A., Benchimol, E., Dubinsky, M., Alex, G., Baldassano, R., Langer, J., Shamberger, R., Hyams, J., Cucchiara, S., Bousvaros, A., Escher, J., Markowitz, J., Wilson, D., van Assche, G. and Russell, R. (2011) Consensus for Managing Acute Severe Ulcerative Colitis in children: A Systematic Review and Joint Statement from ECCO , ESPGHAN, and the Porto IBD Working Group of ESPGHAN. The American Journal of Gastroenterology, 106, 574-588. http://dx.doi.org/10.1038/ajg.2010.481

[11] Kodaira, M., Kajimura, M., Futami, H., et al. (1999) Further Evidence That Exacerbation of Ulcerative Colitis Causes the Onset of Immune Thrombocytopenia: A Clinical Case. The American Journal of Gastroenterology, 94, 1408-1410. http://dx.doi.org/10.1111/j.1572-0241.1999.01098.x

[12] Higuchi, L.M., Joffe, S., Neufeld, E.J., et al. (2001) Inflammatory Bowel Disease Associated with Immune Thrombocytopenic Purpura in Children. Journal of Pediatric Gastroenterology and Nutrition, 33, 582-587. http://dx.doi.org/10.1097/00005176-200111000-00013

[13] Varderili, E., Tülay Sari, Ç., Aslan, V. and Gülbaş, Z. (2003) Resolution of Immune Thrombocytopenic Purpura after Colectomy For Ulcerative Colitis. The Turkish Journal of Gastroenterology, 14, 270-272.

[14] Kathula, S.K., Polenakovik, H., El-Tarabily, M. and Polenakovik, S. (2001) Complete Resolution of Refractory Immune Thrombocytopenic Purpura after Colectomy for Ulcerative Colitis. International Journal of Clinical Practice, 55, 647-648.

[15] Mizuta, Y., Isomoto, H., Kadokawa, Y., et al. (2003) Immune Thrombocytopenic Purpura in Patients with Ulcerative Colitis. Journal of Gastroenterology, 38, 884-890. http://dx.doi.org/10.1007/s00535-002-1166-4

[16] Ahmed, S., Siddiqui, A.K. and Chandrasekaran, V. (2004) Correlation of Thrombotic Thrombocytopenic Purpura Disease Activity with von Willebrand Factor-Cleaving Protease Level in Ulcerative Colitis. American Journal of Medicine, 116, 786-787. http://dx.doi.org/10.1016/j.amjmed.2004.01.020

[17] Puebla Maestu, A., Martin-Lorente, J.L., Lopez-Morante, A., García-Morán, S., Yuguero del Moral, L. and Arauzo González, A. (2003) Ulcerative Colitis Associated with Idiopathic Thrombocytopenic Purpura. Gastroenterología y Hepatología, 26, 545-548. http://dx.doi.org/10.1016/S0210-5705(03)70410-5

[18] Braucci, S., Trappolini, F., Agrisani, L., Luberti, E., Clarice, A., Proietta, M., Pisani, D. and Trappolini, M. (2007) Ul- 
cerative Colitis and Thrombocytopenia: A Clinical Case of Fotuitous Association? La Clinica Terapeutica, 158, 27-30.

[19] Hisada, T., Miyamae, Y., Mizuide, M., Shibusawa, N., Iida, T., Masuo, T., Okada, S., Sagawa, T., Ishizuka, T., Kusano, M. and Mori, M. (2006) Acute Thrombocytopenia Associated with Preexisting Ulcerative Colitis Successfully Treated with Colectomy. Internal Medicine, 45, 87-91. http://dx.doi.org/10.2169/internalmedicine.45.1465

[20] Yong, S., Persad, R., Dower, N., Lees, G. and El-Matary, W. (2008) Idiopathic Thrombocytopenic Purpura after Colectomy for Pediatric Ulcerative Colitis. Inflammatory Bowel Diseases, 14, 1313-1315. http://dx.doi.org/10.1002/ibd.20439

[21] Mares, W.G.N., Gerver, J., Masclee, A.A.M. and Pierik, M. (2011) Anti-TNF Treatment of Ulcerative Colitis Associated with Idiopathic Thrombocytopenic Purpura. Inflammatory Bowel Diseases, 17, 864-865. http://dx.doi.org/10.1002/ibd.21327

[22] Bauer, W., Litchtin, A. and Lashner, B. (1999) Can Colectomy Cure Immune Thrombocytopenic Purpura in a Patient with Ulcerative Colitis? Digestive Diseases and Sciences, 44, 2330-2333. http://dx.doi.org/10.1023/A:1026681426319

[23] Funato, M., Toshiyuki, F., Sasai, H., Hori, T., Terazawa, D., Kubota, K., Ozeki, M., Orii, K., Kaneko, H. and Kondo, N. (2011) Successful Treatment of Pediatric Immune Thrombocytopenic Purpura Associated with Ulcerative Colitis. Pediatrics International, 53, 771-773. http://dx.doi.org/10.1111/j.1442-200X.2010.03308.x

[24] Kappers-Klunne, M.C. and Van’t Veer, M.B. (2001) Cyclosporine A for the Treatment of Patients with Chronic Idiopathic Thrombocytopenic Purpura Refractory to Steroids or Splenectomy. British Journal of Haematology, 114, 121125. http://dx.doi.org/10.1046/j.1365-2141.2001.02893.x

[25] Williams, J.A. and Boxer, L.A. (2003) Combination Therapy for Refractory Idiopathic Thrombocytopenic Purpura in Adolescents. Journal of Pediatric Hematology/Oncology, 25, 232-235. http://dx.doi.org/10.1097/00043426-200303000-00009

[26] Miner, R.J. and Skoog, S.M. (2001) Immune Thrombocytopenic Purpura, Profuse Diarrhea, and New Onset Ulcerative Colitis: A Dramatic Response to Splenectomy. Journal of Clinical Gastroenterology, 32, 276-277. http://dx.doi.org/10.1097/00004836-200103000-00028

[27] Collins, B.W. and Newland, A.C. (1992) Treatment Modalities of Autoimmune Blood Disorders. Seminars in Hematology, 29, 64-74.

[28] Barrie, A. and Plevy, S. (2006) Ttreatment of Immune-Mediated Extraintestinal Manifestations of Inflammatory Bowel Disease with Infliximab. Gastroenterology Clinics of North America, 35, 883-893. http://dx.doi.org/10.1016/j.gtc.2006.09.001

[29] Laharie, D., Bourreille, A., Branche, J., et al. (2012) Ciclosporin versus Infliximab in Patients with Severe Ulcerative Colitis Refractory to Intravenous Steroids: A Parallel, Open-Label Randomized Controlled Trial. The Lancet, 380, 1909-1915. http://dx.doi.org/10.1016/S0140-6736(12)61084-8

[30] Chang, K.H., Burke, J.P. and Coffey, J.C. (2013) Infliximab versus Cyclosporine as Rescue Therapy in Acute Severe Steroid-Refractory Colitis: A Systemic Review and Meta-Analysis. International Journal of Colorectal Disease, 28, 287-293. http://dx.doi.org/10.1007/s00384-012-1602-8

[31] Aloi, M., D’Arcangelo, G., Pofi, F., Vassallo, F., Rizzo, V., Nuti, F., Di Nardo, G., Pierdomenico, M., Viola, F. and Cucchiara, S. (2013) Presenting Features and Disease Course of Pediatric Ulcerative Colitis. Journal of Crohn's and Colitis, 7, e509-e515. http://dx.doi.org/10.1016/j.crohns.2013.03.007

\section{List of the Abbreviations}

Ulcerative Colitis: UC

Idiopathic Thrombocytopenic Purpura: ITP

Inflammatory Bowel Diseases: IBD

Crohn's Disease: CD

Disseminated Intravascular Coagulation: DIC

Cyclosporine A: CyA 
Scientific Research Publishing (SCIRP) is one of the largest Open Access journal publishers. It is currently publishing more than 200 open access, online, peer-reviewed journals covering a wide range of academic disciplines. SCIRP serves the worldwide academic communities and contributes to the progress and application of science with its publication.

Other selected journals from SCIRP are listed as below. Submit your manuscript to us via either submit@scirp.org or Online Submission Portal.
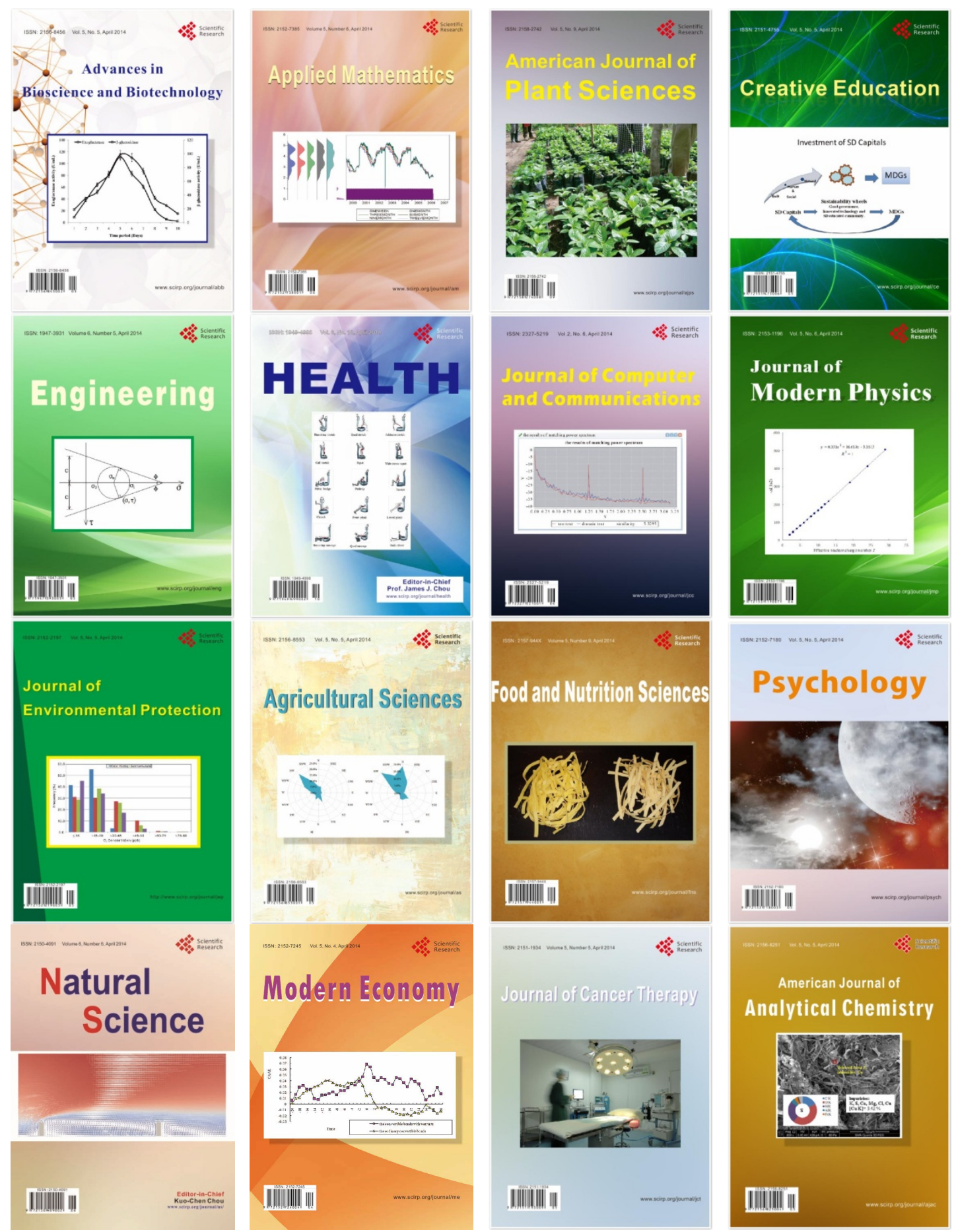